\title{
Chemicals from Lignin by Catalytic Fast Pyrolysis, from Product Control to Reaction Mechanism
}

\author{
Zhiqiang Maa, Victoria Custodis ${ }^{a}$, Patrick Hemberger ${ }^{b}$, Christian Bährlec, Frédéric Vogel ${ }^{c}$, Gunnar \\ Jeschke ${ }^{\mathrm{d}}$, and Jeroen A. van Bokhoven ${ }^{\star a e}$
}

\begin{abstract}
Conversion of lignin into renewable and value-added chemicals by thermal processes, especially pyrolysis, receives great attention. The products may serve as feedstock for chemicals and fuels and contribute to the development of a sustainable society. However, the application of lignin conversion is limited by the low selectivity from lignin to the desired products. The opportunities for catalysis to selectively convert lignin into useful chemicals by catalytic fast pyrolysis and our efforts to elucidate the mechanism of lignin pyrolysis are discussed. Possible research directions will be identified.
\end{abstract}

Keywords: Catalysis · Fast pyrolysis · Lignin · Radicals · Selectivity $\cdot$ Zeolite catalysis

\section{Introduction}

Due to the worldwide demand for renewable energy, lignocellulosic biomass is becoming more and more attractive as feedstock for the production of fuels and commodity chemicals. ${ }^{[1]}$ It is the most abundant and inexpensive sustainable source of carbon, and consists of three main components: lignin, cellulose and hemicellulose. ${ }^{[2]}$ Lignin is the third main component, which constitutes $\sim 40 \%$ by energy and $\sim 15-30 \%$ by weight of the biomass. It has received relatively little attention compared to the other components in biomass with regard to its utility, because lignin depolymerization with selective bond cleavage remains a major challenge for selectively converting it into liquid hydrocarbons and other value-added chemicals. Furthermore, lignin produces more coke/ char than cellulose and hemicellulose. ${ }^{[3]}$ The use of catalysts may overcome these

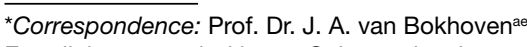
E-mail: jeroen.vanbokhoven@chem.ethz.ch alnstitute for Chemical and Bioengineering ETH Zurich

HCI E 127, Vladimir-Prelog-Weg 1

$\mathrm{CH}-8093$ Zurich

'Molecular Dynamics Group

Paul Scherrer Institute, CH-5232 Villigen PSI

'Research Dept. General Energy

Paul Scherrer Institute, $\mathrm{CH}-5232$ Villigen PSI

'Laboratory for Physical Chemistry

ETH Zurich

HCI F 227, CH-8093 Zürich

eLaboratory for Catalysis and Sustainable Chemistry

Paul Scherrer Institute, $\mathrm{CH}-5232$ Villigen PSI
}

problems and thus provide a solution for lignin conversion to valuable chemicals. Recently, several reviews have been published with regard to the catalytic conversion of lignin in particular. ${ }^{[3 c, 4]}$ Different strategies have been proposed, including non-catalytic pyrolysis, ${ }^{[5]}$ liquid-phase catalytic processing, ${ }^{[6]}$ catalytic fast pyrolysis over acidic zeolites, ${ }^{[7]}$ and catalytic conversion over transition metal oxides ${ }^{[8]}$ and supported transition metal catalysts. ${ }^{[9]}$

In this overview, the opportunities of catalysis for tuning the selectivity for lignin conversion by catalytic fast pyrolysis over different catalysts, such as zeolites, transition metal oxides, and supported transition metals, will be discussed. The objective is to demonstrate the ability to control the selectivity to specific value-added products and to give an overview of catalytic fast pyrolysis of lignin over these catalysts. In addition, we believe that understanding of the complex mechanisms that occur during (catalytic) fast pyrolysis is essential to advance development beyond trial and error.

\section{Catalytic Fast Pyrolysis of Lignin}

\subsection{Zeolite Catalysts}

For lignin catalytic fast pyrolysis over zeolite catalysts, a high catalyst/biomass ratio is required to avoid rapid deactivation of the zeolite catalysts. ${ }^{[1 b, 10]}$ Brønsted acid sites are capable of deoxygenation of the highly oxygenated intermediates formed during pyrolysis. Various studies determined the roles of concentration of acid sites and the pore structure.[7d] Fig. 1 shows typical results of catalytic and noncatalytic lignin pyrolysis. The solid phase consisted mainly of char/coke, and the gas phase of carbon monoxide, carbon dioxide, and methane. The liquid product contains different organic and inorganic compounds and water (detail of the product analysis in ref. [7d]). In the case of zeolite as a catalyst, char is the main solid product during fast pyrolysis. ${ }^{[11]}$ The composition of liquid products by catalytic fast pyrolysis strongly depended on the presence of acid sites. Zeolites, such as H-ZSM5, converted alkoxy aromatics and alkoxy phenols into aromatics and phenol through dealkoxylation. Phenols were not easily further deoxygenated, and they were only converted over zeolites with a high number of acid sites. These transformations are acid catalyzed and do not occur over non-acidic catalyst, such as silicalite. On an acid site, dehydration of phenol occurs, resulting in the formation of water and a benzenium ion on the zeolite, which might rapidly react further via hydride transfer. As a result, aromatics such as benzene, toluene, xylene (BTX), and naphthalene are formed as the main aromatic compounds. In addition, acid zeolites are reported as active in conversion of olefin to aromatics. ${ }^{[8,12]}$ Thus, by tuning the nature and amount of the active sites in the catalysts, the selectivity and the yield can be partially controlled.

No significant influence on the liquid yield and product distribution was observed with non-porous, non-acidic $\mathrm{SiC}$ compared to that of pyrolysis in the absence of a catalyst ('without' in Fig. 1). The liquid yield increased to above $50 \mathrm{wt} . \%$ and the yield of solid decreased to about $35 \mathrm{wt} . \%$ (Fig. 1a) over porous catalysts without acid sites such as Na-ZSM5(25) and silicalite. However, similar liquid product distribution as in the non-catalytic pyrolysis was observed: phenol alkoxy was the main 


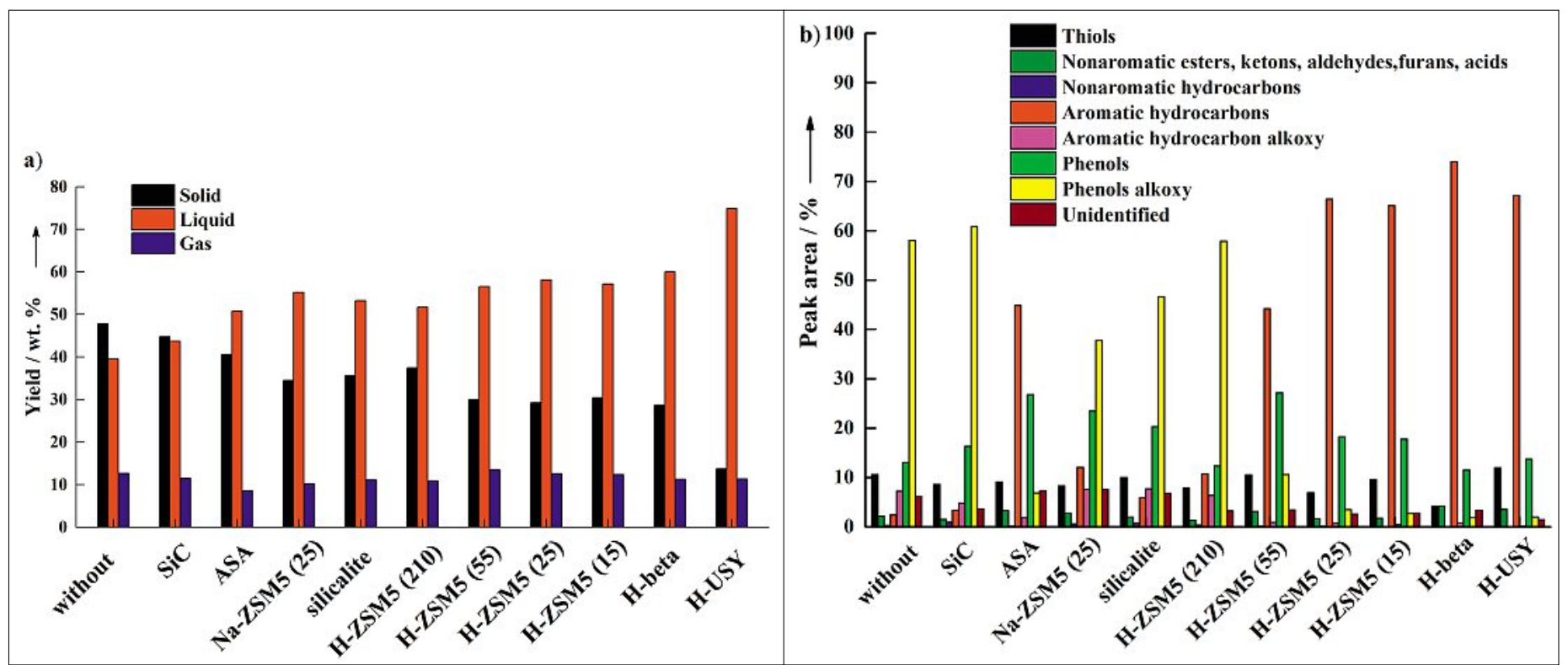

Fig. 1. The effect of acidity and pore structure on yield and product distribution during lignin fast pyrolysis at 80 wt.\% of catalyst loading. a) Yield of solid, liquid, and gas, wt.\%; b) composition of liquid fraction, based on relative peak area. With permission of Elsevier from ref. [7d].

component (Fig. 1b). Secondary catalytic conversion of phenol alkoxys into phenols and aromatic hydrocarbons was prevented with a catalyst lacking acid function, and the initially formed products were also prevented from secondary reactions to form the coke/char. In the case of catalyst with merely acid sites without zeolite cages, such as amorphous silica alumina (ASA), no such stabilization occurred. Due to acid sites present in the catalysts, phenol and aromatic hydrocarbons were formed from the intermediates by catalytic transformation, thus the yield of liquid increased and the yield of solid decreased. The difference between each ZSM5 catalyst is the acidity, indicated by the $\mathrm{Si}$ to $\mathrm{Al}$ ratio in the brackets. The gradual introduction of more acid sites into H-ZSM5 caused a systematic, increased selectivity to deoxygenated products. H-ZSM5 with low Si to Al ratio, such as 25 or 15 , was effective in the selective deoxygenation of oxygen containing organic molecules, resulting in the formation of aromatics. ${ }^{[13]}$ The amount of phenols showed a maximum with a catalyst at intermediate $\mathrm{Si} / \mathrm{Al}$ ratio of 55 . Therefore, the selectivity to the final product can be tuned by changing the number and the strength of acid sites in the catalysts. Low $\mathrm{Si} / \mathrm{Al}$ ratio (high number of acid sites and strength) favors the formation of aromatic hydrocarbons; while high $\mathrm{Si} / \mathrm{Al}$ ratio shows little effect on the product distribution compared to that without catalyst and with non-acidic catalyst. Phenols are the intermediate products and are obtained with high percentage over medium $\mathrm{Si} / \mathrm{Al}$ ratio. Not only the number of sites, but also the pore size of the catalyst influenced the yield of liquid. The high yield of liquid was obtained with a large pore size catalyst, as shown by zeolites with decreasing pore sizes: H-USY $(7.4 \AA)$ > H-beta $(6.6 \AA)>$ H-ZSM5 (5.5 $\AA$ ) in Fig. 1. The majority of the aromatic product was obtained inside the zeolite pores of the medium and large pore zeolites. ${ }^{[14]}$ It is likely that the large pore opening in H-USY (Fig. 1a) enables adsorption and thus reaction of the larger molecules, preventing their secondary conversion and char formation. Conversion over small pore zeolites is likely caused by adsorption on the surface or partial entering of the pores so catalytic conversion occurs. Overall, acid sites yielded increasing fraction of liquid product, which primarily consisted of aromatic hydrocarbons. A liquid yield of over 70 wt.\% was achieved over the H-USY zeolite, which mainly consisted of benzene, xylenes, and toluene (Fig. 1).

\subsection{Metal Oxide Catalysts}

Metal oxides have been widely studied for hydrodeoxygenation (HDO) of bio-oils and they exhibited excellent activity and selectivity. ${ }^{[15]}$ Fig. 2 shows the yields of solid, liquid, and gas during catalytic fast pyrolysis of lignin over transition metal oxides. The yields of solids increased over nickel oxide and iron oxide catalysts, compared to pyrolysis without catalyst (Fig. $2 a)$. The yield of the solid was slightly reduced and the yield of liquid increased over manganese oxide, cobalt oxide and copper oxide, except for molybdenum oxide. Over this catalyst, a large amount of gas was produced, which mainly consists of carbon dioxide. Low yield of liquid was obtained in the presence of iron oxide, which was due to the inhibition of decomposition reaction of organic compounds. ${ }^{[15 a]}$ Fig. $2 b$ shows the liquid products distri- bution over these metal oxide catalysts. Phenol alkoxys were the main products over transition metal oxides. This product distribution is similar to that without a catalyst, with the exception of cobalt oxide, which is a deoxygenation catalyst, producing $\sim 30 \%$ of aromatic hydrocarbon alkoxy and $\sim 30 \%$ phenols alkoxy. A similar liquid products distribution was obtained over iron oxide and manganese oxide compared to those without a catalyst (Fig. 2b), suggesting these catalysts are not active for catalytic fast pyrolysis of lignin; the highest amount of 2-methoxy phenol is produced over nickel oxide; on the contrary, more vanillin (over 30\%) than 2-methoxy phenol and phenols is produced over copper oxide and molybdenum oxide. A selective extraction would be a significant gain in value from economical point of view. Cobalt oxide is active for the production of aromatic alkoxy hydrocarbons, such as 1,3-benzodioxole, 3,4-dimethoxy benzene and toluene, and for the reduction of phenol and alkoxy phenol.

\subsection{Zeolite-supported Metal Catalysts}

Fig. 3 shows the results of catalytic fast pyrolysis over zeolite-supported transition metals. The yield of solid decreased, that of liquid increased, while the yield of gas remained the same compared to yields obtained without catalyst. The large surface area and pore volume of the zeolite helps stabilize intermediates, increasing the liquid fraction, as shown above.[7d] In the presence of the zeolite-supported catalysts, the liquid products distribution changed drastically (Fig. 3b). Aromatic hydrocarbons, phenols, and phenols alkoxy were produced with similar yield over 


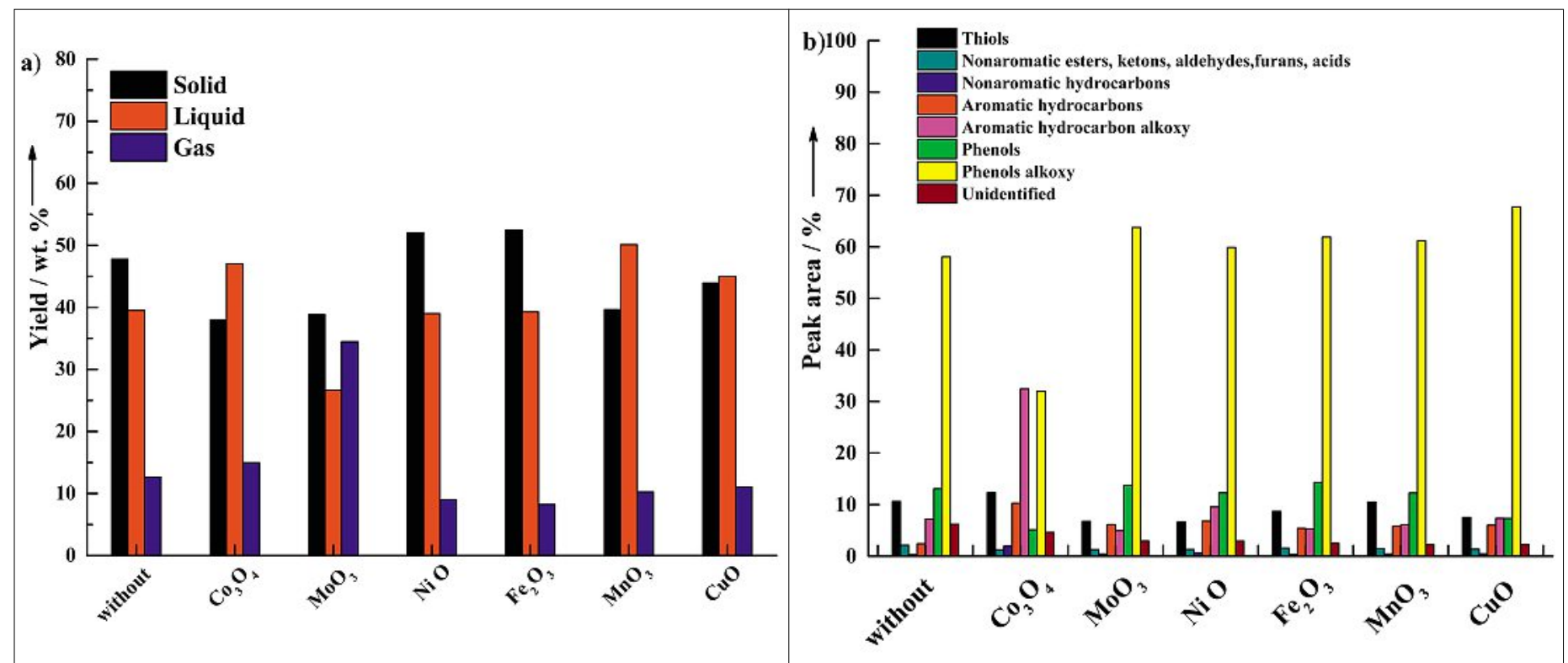

Fig. 2. The effect of transition metals on yield and product distribution during lignin fast pyrolysis at $80 \mathrm{wt}$ \% of catalyst loading. a) Yield of solid, liquid, and gas, wt.\%; b) composition of liquid fraction, based on relative peak area. With permission of the Royal Society of Chemistry from ref. [16].

supported molybdenum and iron oxides catalysts; each around $30 \%$. The metal ions probably interacted with the acid sites during preparation of the zeolite-supported catalyst by impregnation, which caused the decrease of the number of acid sites. The catalysts after impregnation were obtained in lowered acidic activity, because the acid site is the active site to produce aromatic hydrocarbons from biomass by fast pyrolysis. ${ }^{[1 b, 7 c, 7 d, 8,17]}$ For supported manganese, copper, nickel, and cobalt catalysts, partial loss of acid sites was observed. However, the aromatic hydrocarbons remain as the main products, and a small amount of phenols alkoxy is also present. Significant amounts of aromatic hydrocarbons are also produced over supported nickel and cobalt catalyst, even on the sodium-form zeolite; clearly, these two metals catalyze the formation of aromatic hydrocarbons under the pyrolysis conditions.

Scheme 1 shows a general reaction scheme for lignin non-catalytic and catalytic fast pyrolysis. It identifies the role of catalysis and the partial control of the selectivity to the final products. The most abundant compounds in the liquid fraction over different catalysts are indicated. Under non-catalytic fast pyrolysis condi- tions, lignin decomposes under heat and generates depolymerization products, following a radical reaction mechanism. ${ }^{[18]}$ These radicals are highly reactive and can rapidly repolymerize to form undesired solid or be stabilized to form stable products, such as phenols alkoxy and phenols. Over transition metal oxides, alkoxy phenols are the main products, however, the relative ratio between oxygenated compounds varies significantly. Over zeolitesupported cobalt and nickel catalysts, the formation of aromatic hydrocarbons is enhanced. ${ }^{[16]}$ The intermediates are stabilized by adsorption in the pores in the presence

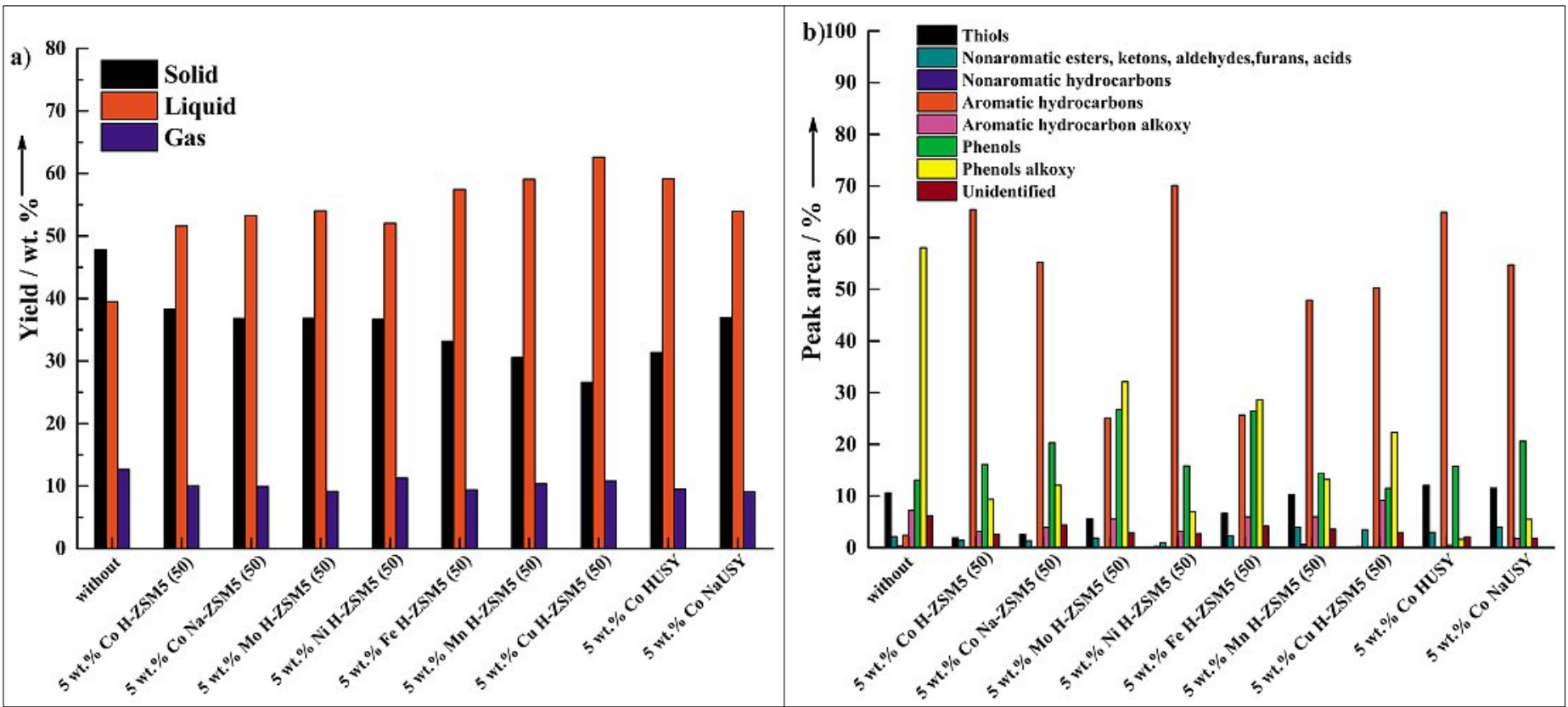

Fig. 3. The effect of zeolite-supported transition metals on yield and product distribution during lignin fast pyrolysis at 80 wt.\% of catalyst loading. a) Yield of solid, liquid, and gas, wt.\%; b) composition of liquid fraction, based on relative peak area. With permission of the Royal Society of Chemistry from ref. [16]. 


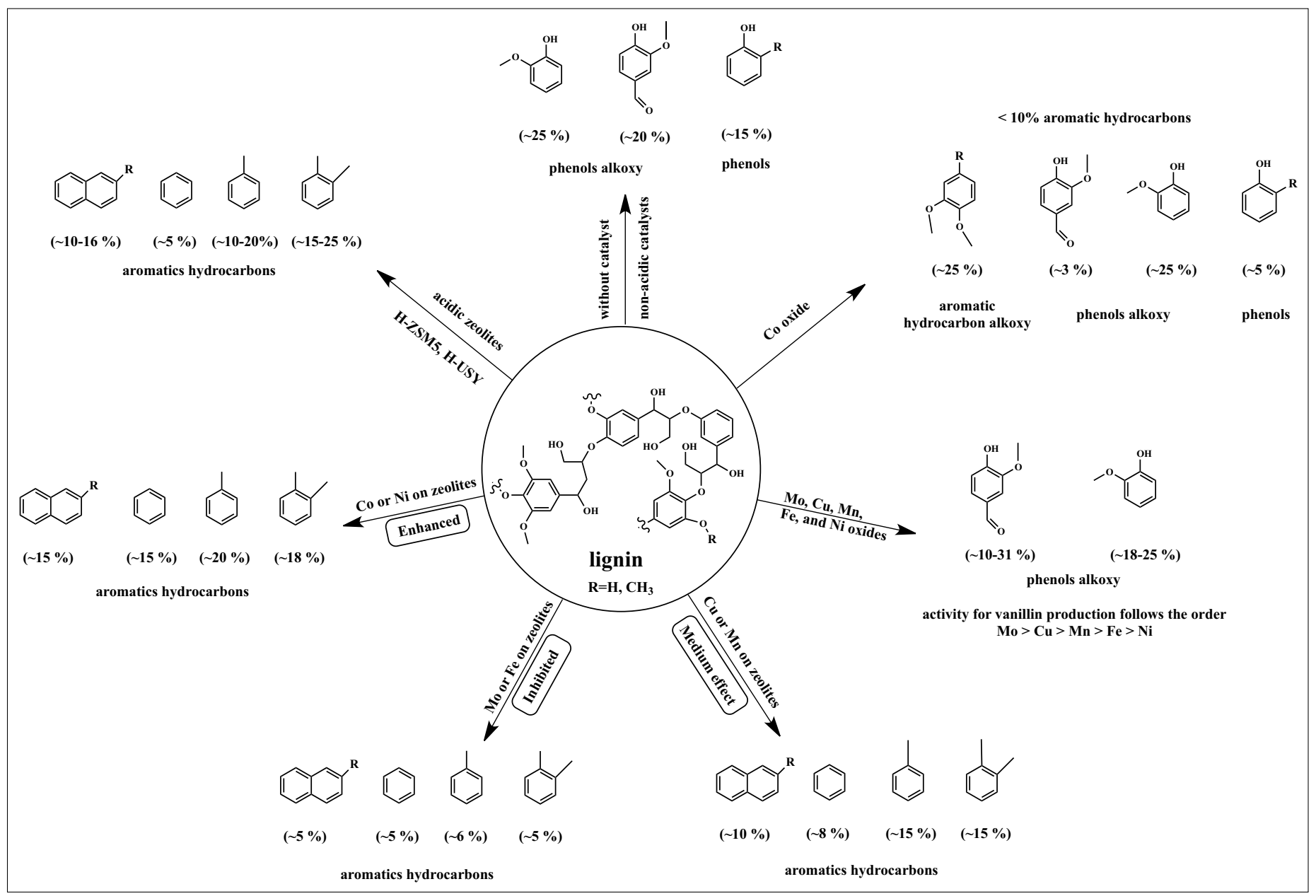

Scheme 1. Selectivity to most abundant liquid products of lignin non-catalytic/catalytic fast pyrolysis (number in parentheses) are the yields based on peak area in GC/MS. With permission of the Royal Society of Chemistry from ref. [16].

of porous materials without acidic function, such as silicalite, thus increasing the yield of liquid without changing the liquid products distribution. In the presence of strong acidic zeolites, such as H-USY and $\mathrm{H}-\mathrm{ZSM} 5$ with low $\mathrm{Si}$ to $\mathrm{Al}$ ratio, complex reactions are involved, such as dehydration, decarboxylation, dealkylation, cracking, isomerization, oligomerization, etc. Aromatic hydrocarbons are the final products of such transformations. ${ }^{[7 \mathrm{~d}, 8,10 \mathrm{a}]}$ Phenols are intermediate products, the amount of which can be controlled to some extent by modification of the acid function and by introduction of transition metals, such as molybdenum and iron into the acidic zeolites.

\section{Fast Pyrolysis Chemistry}

A fundamental understanding of the properties of lignin and the chemistry of the reactions taking place during pyrolysis is essential to rationally design or optimize the process and the catalyst. However, pyrolysis follows a complex multi-reaction radical mechanism and lignin is a very complex polymer with irregular structure. ${ }^{[3 \mathrm{c}]}$ Moreover, to gain meaningful results in situ observation of the pyrolysis reactions at high temperatures is necessary but not trivial to perform. Reactive radicals are formed by the thermal dissociation of chemical bonds within the lignin polymer. The recombination of these radicals can lead to new compounds and eventually tar, resulting in low yield of the desired pyrolysis products. To gain insight into what radicals form during pyrolysis, ex situ and in situ electron paramagnetic resonance spectroscopy (EPR) was applied. Ex situ EPR measurements of radicals in pyrolytic chars indicated that radicals started to form at temperatures around $300{ }^{\circ} \mathrm{C}$ as shown in Fig. 4.

Fig. 4 shows the result of in situ EPR measurements of poplar (hardwood) and pine (softwood) Klason lignins pyrolysis at high temperature, which indicated that the radical formation under pyrolytic conditions started between $250{ }^{\circ} \mathrm{C}$ and $350{ }^{\circ} \mathrm{C} .{ }^{[19]}$ About $6 \cdot 10^{16}$ radicals $/ g$ are present in wood corresponding to about 2 to $3 \cdot 10^{17}$ radicals/g in the lignin fraction before pyrolysis.[20] Klason and Dioxan extraction of the lignin preserves this radical concentration, whereas the Organosolv process that takes place at $200{ }^{\circ} \mathrm{C}$ leads to an about tenfold increase in radical concen- tration. ${ }^{[19]}$ By high-field EPR spectroscopy it could be shown that these stable radicals existing before pyrolysis are most likely ortho-semiquinone radicals in different states with the speciation depending on the $\mathrm{pH}$ value during extraction. Speciation can also be changed after extraction by treatment with acids or bases. Under pyrolysis, significant differences in the radical formation were observed for hardwood lignin, which contains large amounts of syringyl units (dimethoxy-phenols), and softwood-based lignin, which almost exclusively contains guaiacyl units (methoxy-phenols). [19] Syringyl-derived radicals seem to be more stable and undergo fewer recombination reactions. Therefore hardwood lignin pyrolysis typically yields less char. ${ }^{[19]}$ By EPR investigations of the gas phase, Kibet et al. showed that volatile radical fragments with low molecular weight were formed during pyrolysis. ${ }^{[21]}$ These radicals can end up in the condensed pyrolysis products and may influence their stability. A recent study by Kim et al. showed that the majority of radicals contained in pyrolysis oil from wood are the products of lignin pyrolysis. ${ }^{[22]}$ However, it seems that those radicals are stable and do not influence the stability of the liquid 
obtained after pyrolysis towards repolymerization, at least on the short term.

Catalytic/non-catalytic pyrolysis of lignin comprises a very complex set of reactions due to the wide variety of bonds and monomers in the lignin matrix. ${ }^{[23]}$ The primary depolymerization process is not dominated with any catalyst, but by the radical formation in the lignin polymer upon pyrolysis and recombination of intermediates and radicals. An additional difficulty is that the structure and composition of lignin is highly dependent on the origin and the isolation methods applied. Therefore, model compounds of increasing complexity were used and their decomposition was studied to determine the mechanisms and dominant reactions during depolymerization under various conditions. ${ }^{[19,20,24]}$ Scheme 2 shows the pyrolysis of model compounds under high-vacuum conditions. By applying imaging photoelectron photoion coincidence (iPEPICO) spectroscopy with vacuum ultraviolet (VUV) synchrotron radiation, we are able to isomer-selectively detect reactive intermediates and determine the decomposition mechanism of lignin model compounds while suppressing secondary reactions of the radicals. ${ }^{[25]}$ These results are compared to those of fast pyrolysis at ambient pressure in a py-GC/MS setup.

Fig. 4 shows the reaction mechanism and detected products of model compounds under different pyrolysis conditions. Guaiacol is a prominent lignin model compound and thoroughly studied in literature. ${ }^{[24,26]}$ Radicals are formed by homolytic fission of the weakest bond followed by decarbonylation. ${ }^{[26 b, 27]}$ However, as soon as there are other radicals present, hydrogen radicals are abstracted and rearrangement reactions become dominant. ${ }^{[24,28]}$ Diphenyl ether, a model substance for the $\alpha-\mathrm{O}-4$ ether bond in lignin, directly forms phenyl- and phenoxy-radicals, which recombine easily leading to char formation, in contrast to guaiacol. In a radical-rich environment, diphenylether rather recombines due to the unstable nature of the intermediates. As soon as a methoxy group is attached to diphenylether, there are no recombination reactions anymore, but the intermediate is stabilized by hydrogen abstraction/addition and even rearrangement including a 1,2-phenyl shift. These pressure and temperature reaction patterns are well represented in actual lignin pyrolysis. Several lignins show a similar trend, such as hardwood lignin (poplar) and softwood lignin (pine). Since hardwoods contain more syringyl-subunits (dimethoxy-phenols), they form more monomers upon pyrolysis: on the one hand the formed radicals are less prone to recombination and more stable (as is guaiacol compared to DPE); on the other hand hardwoods contain fewer $\mathrm{C}-\mathrm{C}$ bonds, which are thermally more stable and increase char formation. ${ }^{[29]}$ Hardwoods produce more ketones and aldehydes at low temperature $\left(<550{ }^{\circ} \mathrm{C}\right)$ and fewer phenols at high temperatures than softwoods (Fig. 4).

\section{Outlook}

\subsection{Catalysts}

Generally, the selectivity varies strongly with the type of lignin and reaction conditions (Fig. 1b, 2b, 3b, and Scheme 1), which poses many challenges. In situ EPR measurements and model compounds studies (Fig. 4 and Scheme 2) reveal that there are two main decomposition routes: first, the homolytic fission of the weakest bond-forming radicals and, second, the radical initiation leading to different radicals, which further rearrange or recombine

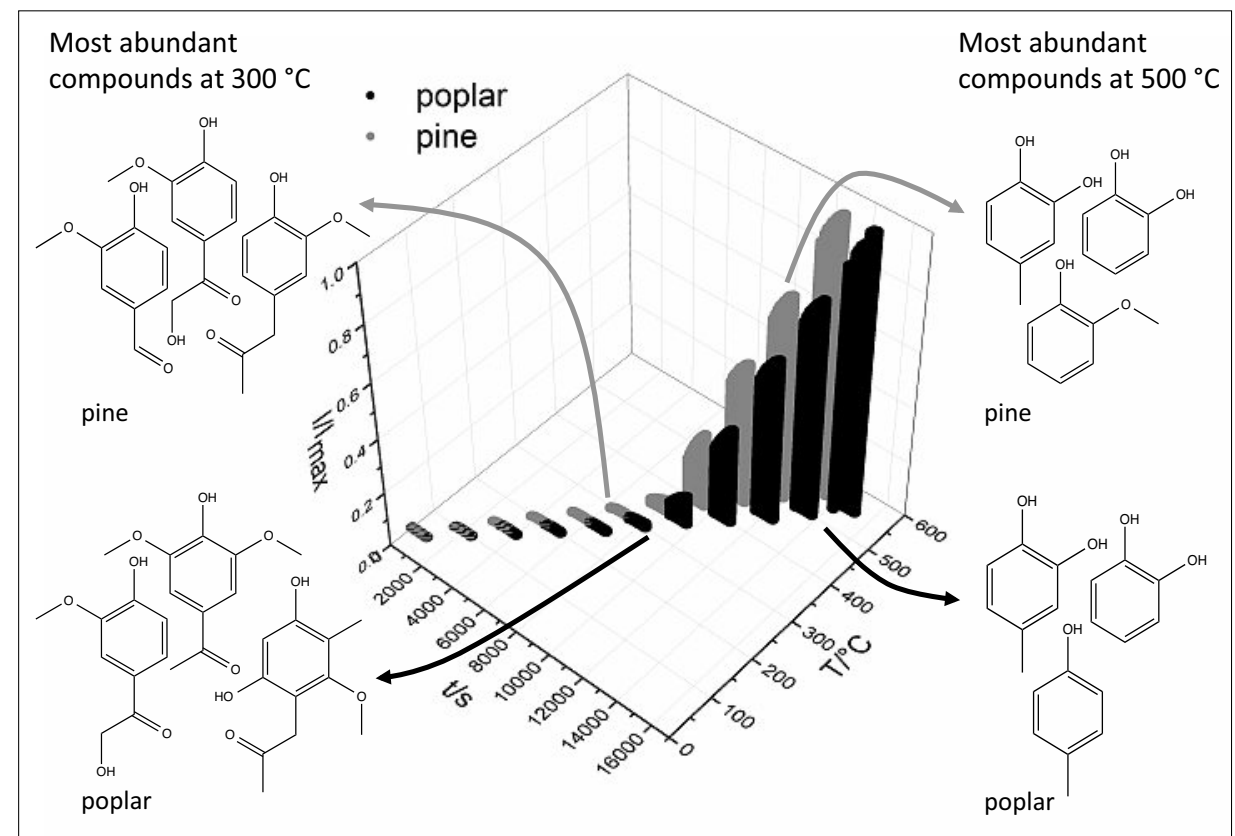

Fig. 4. Normalized radical concentration of poplar (hardwood) and pine (softwood) Klason lignin during pyrolysis and the most abundant stable organic compounds at 300 and $500{ }^{\circ} \mathrm{C}$. With permission of Wiley-VCH from ref. [19].

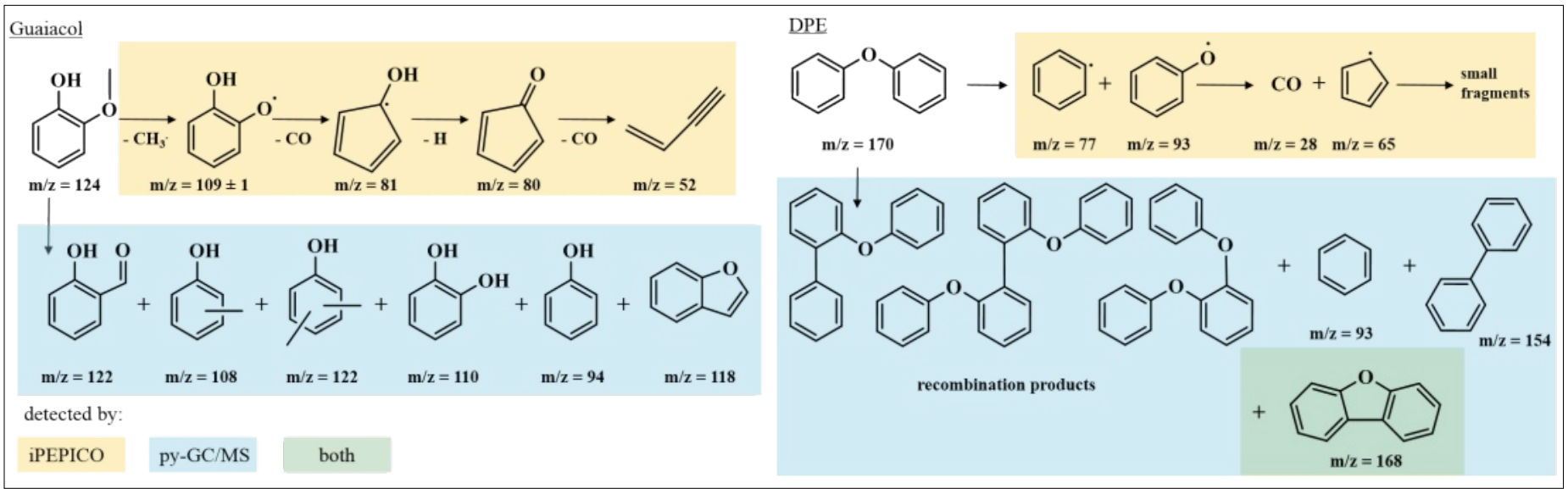

Scheme 2. Reaction mechanism and detected products of model compounds pyrolysis under vacuum (by iPEPICO) and ambient (by py-GC/MS) conditions. left) guaiacol and right) dimethylether (DPE). With permission from ref. [24]. Copyright American Chemical Society 2014. 
depending on the nature of the radicals. The most relevant reaction step in lignin pyrolysis is therefore the primary radical formation, which then initiates further reactions. If stabilization of these primary intermediates in lignin were possible, the product selectivity of lignin could be tuned towards much more desired chemicals with the help of catalysis. The results indicate that there is significant potential to control the selectivity by variation of catalysts and reaction conditions using additives. Multifunctionality of the catalyst is required for this process. Firstly, the catalyst should be able to activate the initial pyrolysis products, especially oxygen-containing molecules. Secondly, the catalyst must show a high selectivity to target products, which can significantly reduce the cost of further separation/purification processes. Furthermore, the catalysts should be stable under the reaction conditions and for long-time operation, which can reduce the cost of the catalyst itself.[10b,30] Besides the development of new catalysts, research should focus on the understanding of the reaction mechanism and designing a new catalytic system. It is a great challenge to meet the requirements for the development of new catalysts and catalytic systems, but the opportunities for tuning the selectivity during lignin catalytic fast pyrolysis are also great. Because of the structural complexity of lignin, it makes no sense to aim at reaching complete selectivity. There is significant potential to further increase yields to specific classes of products, such as phenols and aromatics.

\subsection{Engineering}

There are large differences in products between vacuum pyrolysis and ambient pyrolysis. Thus, process conditions (dis) favoring secondary bimolecular reactions may be used as a tool to control the reactions. The pressure plays an important role in this process, so far, virtually all the studies employ standard conditions, such as pyrolysis under ambient pressure in small reactors. Therefore, significant efforts should be devoted to the engineering aspects of the process.

\section{Acknowledgments}

Financial supports by the Swiss National Science Foundation (NRP66, no. 406640136892) and the Swiss Federal Office for Energy (BFE contract number 101969/152433) are gratefully acknowledged. Some of the measurements were carried out at the VUV $(\mathrm{x} 01 \mathrm{db})$ beamline of the Swiss Light Source located at Paul Scherrer Institute.

Received: July 28, 2015

[1] a) S. Czernik, A. V. Bridgwater, Energy Fuels 2004, 18, 590; b) T. P. Vispute, H. Zhang, A. Sanna, R. Xiao, G. W. Huber, Science 2010, 330, 1222; c) M. M. Wright, D. E. Daugaard, J. A. Satrio, R. C. Brown, Fuel 2010, 89, S2.

[2] Y. Sun, J. Cheng, Bioresour. Technol. 2002, 83,1 .

[3] a) D. Mohan, C. U. Pittman, Jr., P. H. Steele, Energy Fuels 2006, 20, 848; b) A. Demirbas, Energy Sources, Part A 2009, 31, 1186; c) J. Zakzeski, P. C. A. Bruijnincx, A. L. Jongerius, B. M. Weckhuysen, Chem. Rev. 2010, 110, 3552.

[4] a) G. W. Huber, S. Iborra, A. Corma, Chem. Rev. 2006, 106, 4044; b) P. M. Mortensen, J. D. Grunwaldt, P. A. Jensen, K. G. Knudsen, A. D. Jensen, Appl. Catal. A 2011, 407, 1.

[5] C. Amen-Chen, H. Pakdel, C. Roy, Bioresour. Technol. 2001, 79, 277.

[6] J. N. Chheda, G. W. Huber, J. A. Dumesic, Angew. Chem. Int. Ed. 2007, 46, 7164.

[7] a) R. K. Sharma, N. N. Bakhshi, Fuel Process. Technol. 1993, 35, 201; b) P. de Wild, R. van der Laan, A. Kloekhorst, E. Heeres, Environ. Prog. Sustainable Energy 2009, 28, 461; c) D. J. Mihalcik, C. A. Mullen, A. A. Boateng, $J$. Anal. Appl. Pyrolysis 2011, 92, 224; d) Z. Ma, E. Troussard, J. A. van Bokhoven, Appl. Catal. A 2012, 423, 130.

[8] C. A. Mullen, A. A. Boateng, Fuel Process. Technol. 2010, 91, 1446.

[9] a) C. Zhao, Y. Kou, A. A. Lemonidou, X. Li, J. A. Lercher, Angew. Chem. Int. Ed. 2009, 48, 3987; b) C. Zhao, J. He, A. A. Lemonidou, X. Li, J. A. Lercher, J. Catal. 2011, 280, 8; c) C. Zhao, J. A. Lercher, Angew. Chem. Int. Ed. 2012, 51, 5935; d) C. Zhao, J. A. Lercher, ChemCatChem 2012, 4, 64.

[10] a) T. R. Carlson, G. A. Tompsett, W. C. Conner, G. W. Huber, Top. Catal. 2009, 52, 241; b) Z. Ma, J. A. van Bokhoven, ChemCatChem 2012, 4, 2036.

[11] S. Wan, C. Waters, A. Stevens, A. Gumidyala, R. Jentoft, L. Lobban, D. Resasco, R. Mallinson, S. Crossley, ChemSusChem 2015, 8, 552.

[12] J. D. Adjaye, N. N. Bakhshi, Fuel Process. Technol. 1995, 45, 185 .
[13] T. R. Carlson, T. P. Vispute, G. W. Huber, ChemSusChem 2008, 1, 397.

[14] J. Jae, G. A. Tompsett, A. J. Foster, K. D. Hammond, S. M. Auerbach, R. F. Lobo, G. W. Huber, J. Catal. 2011, 279, 257.

[15] a) J. Shao, R. Yan, H. Chen, H. Yang, D. H. Lee, Fuel Process. Technol. 2010, 91, 1113; b) C. A. Mullen, A. A. Boateng, Fuel Process. Technol. 2010, $91,1446$.

[16] Z. Ma, V. Custodis, J. A. van Bokhoven, Catal. Sci. Technol. 2014, 4, 766.

[17] M. Guisnet, P. Magnoux, D. Martin, in Stud. Surf. Sci. Catal., Vol. 111, Eds. C. H. Bartholomew, G. A. Fuentes, Elsevier, 1997, pp. 1.

[18] a) R. J. Evans, T. A. Milne, M. N. Sotlys, J. Anal. Appl. Pyrolysis 1986, 9, 207; b) P. F. Britt, A. C. Buchanan, III, K. B. Thomas, S.-K. Lee, J. Anal. Appl. Pyrolysis 1995, 33, 1; c) P. F. Britt, A. C. Buchanan, III, M. J. Cooney, D. R. Martineau, J. Org. Chem. 2000, 65, 1376; d) C. Amen-Chena, H. Pakdelb, C. Roy, Bioresour. Technol. 2001, 79, 277.

[19] C. Bährle, V. Custodis, G. Jeschke, J. A. van Bokhoven, F. Vogel, ChemSusChem 2014, 7, 2022.

[20] C. Bährle, T. U. Nick, M. Bennati, G. Jeschke, F. Vogel, J. Phys. Chem. A 2015, DOI: 10.1021/ acs.jpca.5b02200.

[21] J. Kibet, L. Khachatryan, B. Dellinger, Environ. Sci. Technol. 2012, 46, 12994.

[22] K. H. Kim, X. Bai, S. Cady, P. Gable, R. C. Brown, ChemSusChem 2015, 8, 894.

[23] J. E. White, W. J. Catallo, B. L. Legendre, J. Anal. Appl. Pyrolysis 2011, 91, 1.

[24] V. B. F. Custodis, P. Hemberger, Z. Ma, J. A. van Bokhoven, J. Phys. Chem. B 2014, 118, 8524.

[25] a) A. Bodi, P. Hemberger, T. Gerber, B. Sztáray, Rev. Sci. Instrum. 2012, 83, 083105; b) M. Johnson, A. Bodi, L. Schulz, T. Gerber, Nucl. Instru. Meth. Phys. Res. Sect. A 2009, 610, 597; c) A. Bodi, M. Johnson, T. Gerber, Z. Gengeliczki, B. Sztáray, T. Baer, Rev. Sci. Instrum. 2009, 80, 034101.

[26] a) R. N. Olcese, J. Francois, M. M. Bettahar, D. Petitjean, A. Dufour, Energy Fuels 2013, 27, 975; b) A. M. Scheer, C. Mukarakate, D. J. Robichaud, M. R. Nimlos, G. B. Ellison, J. Phys. Chem. A 2011, 115, 13381.

[27] A. M. Scheer, C. Mukarakate, D. J. Robichaud, M. R. Nimlos, H.-H. Carstensen, G. Barney Ellison, J. Chem. Phys. 2012, 136, 044309.

[28] E. Dorrestijn, P. Mulder, J. Chem. Soc., Perkin Trans. 2 1999, 777.

[29] D. Dimmel, in 'Lignin and Lignans: Advances in Chemistry', Eds. C. Heitner, D. Dimmel, J. Schmidt, CRC Press, 2010, pp. 1.

[30] Z. Ma, J. van Bokhoven, in 'Catalysis', Vol. 26, The Royal Society of Chemistry, 2014, pp. 249. 